\title{
A VIOLÊNCIA DE GÊNERO COMO ELEMENTO DISCRIMINADOR NOS CRIMES COMETIDOS CONTRA A MULHER EM SEU AMBIENTE DOMÉSTICO E FAMILIAR
}

\author{
Luiz Renato Mendonça Zissmann, Eduardo Buzetti Eustachio Bezerro
}

Universidade Do Oeste Paulista - UNOESTE, curso de Direito, Presidente Prudente, SP. E-mail:

luizzissmann@hotmail.com

\section{RESUMO}

Os crimes cometidos com violência de gênero contra a mulher em seu ambiente doméstico e familiar não se restringe apenas nas disposições contidas em lei, logo, o presente artigo tem como objetivo apresentar a interpretação contida no artigo 5o da Lei 11.340 de 2006 expondo os elementos necessário para a imposição da lei especial em situações comuns existentes na doutrina e jurisprudência, tendo em vista o novo remodelamento de conceito familiar. O método utilizado foi o dedutivo legal composto por auxilio doutrinário, jurisprudencial, e analise de casos fáticos vinculados à experiência prática de casos reais presenciados em sala de audiência frente as partes conflitantes. Conclui-se que a interpretação do conceito legal de violência doméstica se destaca com a adaptação do modelo familiar brasileiro, respeitando as adversidades e equiparando as minorias através do princípio da igualdade material contido na Constituição Federal de 1988.

Palavras chaves: Violência de gênero. Ambiente doméstico e familiar. Lei 11.340 de 2006. Violência doméstica. Igualdade material.

\section{GENDER VIOLENCE AS A DISCRIMINATORY ELEMENT IN CRIMES AGAINST WOMEN IN THEIR DOMESTIC AND FAMILY ENVIRONMENT}

\begin{abstract}
The crimes committed with gender-based violence against women in their domestic and family environment do not only restrict the provisions contained in the law, so the purpose of this article is to present the interpretation contained in article 5 of Law 11.340 of 2006, setting out the elements necessary for The imposition of the special law on existing situations in the doctrine and jurisprudence in view of the new remodeling of family concept. The method used was the legal deductive composed of doctrinal assistance, case law, and analysis of phatic cases linked to the practical experience of real cases witnessed in the courtroom before the conflicting parties. It is concluded that the interpretation of the legal concept of domestic violence stands out with the adaptation of the Brazilian family model respecting adversities and equating minorities through the principle of material equality contained in the Federal Constitution of 1988. Keywords: Gender violence. Domestic and family environment. Law 11,340 of 2006. Domestic violence. Material equality
\end{abstract}

\section{INTRODUÇÃO}

A Lei 11.340 de 2006 popularmente conhecida como Lei Maria da Penha foi recepcionada pelo Brasil após imposições de tratados internacionais que esperava medidas de rigor para a diminuição dos crimes cometidos contra a mulher no ambiente doméstico e familiar por decorrência do gênero.

Em que pese as discussões sobre a sua constitucionalidade, que por sua vez já foram consolidadas diante do princípio da igualdade material em tratar os iguais como iguais e desiguais 
como desiguais na medida em que desigualam, verifica-se através de ações afirmativas que mesmo após dez anos da criação da lei muito ainda se questiona sobre quais fatos a lei se enquadra.

Ocorre que os crimes cometidos em razão do gênero em ambientes domésticos e familiares não se limita apenas à mulher, havendo a necessidade da interpretação extensiva para outras minorias, vítimas de violência de gênero existentes na sociedade, como os idosos, as criança e adolescente e as relações homoafetivas.

Logo, o presente estudo tem como objetivo apresentar a interpretação da igualdade material e discriminação por violência de gênero, como fundamento necessário para a imposição de medias rigorosa em lei especial, afim de se encontrar a melhor forma de identificar os crimes cometidos dentro do ambiente doméstico e familiar contidos na Lei 11.340/2006.

\section{METODOLOGIA}

O presente estudo seguirá os métodos dialético-dedutivo, com emprego de pesquisa à legislação, doutrina e jurisprudência acerca da matéria objeto da investigação.

\section{RESULTADOS}

Os resultados do presente estudo se concluíu mediante o auxílio doutrinário e jurisprudencial, na oportunidade em que restou justificado que a violência de gênero é existente nas famílias brasileiras e o tratamento desigual para as mulheres abarcado com o advento da Lei 11.340 de 2006 é constitucional.

\section{A INCORPORAÇÃO DOS DIREITOS HUMANOS DAS MULHERES NO ORDENAMENTO JURÍDICO BRASILEIRO}

O conceito Aristotélico de justiça se faz presente em grande parte dos basilares constitucionais da sociedade como forma de tratar os iguais como iguais e os desiguais como desiguais na medida em que desigualam.

No ordenamento jurídico constitucional brasileiro, o princípio da igualdade se fez presente no ano de 1824, com o artigo 179, inciso XIII e na Constituição Federal de 1934. (SARLET, 2016, p.572)

Desde então, após diversas ratificações do conceito de igualdade, a Constituição Federal de 1988 aduziu o conceito formal de igualde no artigo 50, inciso I, restando evidente a presença da igualdade material precedida da observância das minorias em vários dispositivos no corpo constitucional, tais como; art. $7^{\circ}$, incisos XVIII e XIX: art. 40, § 1ㅇ: art. 143, §§ 1으 e 2ㅇ: art. 201, § 70 (MORAIS, 2013, p.37).

Ocorre que mesmo diante da evolução constitucional e ratificação de tratados internacionais, verificou-se que a República Federativa do Brasil permanecia tolerante em relação ao assunto de violência doméstica, "daí por que o advento da Lei n.11.340, de 7 de agosto de 2006, que entrou em vigor no dia 22 de setembro de 2006, constituiu avanço inovador do Brasil em sede de Direitos Humanos" (JESUS, 2015, p.52).

A imposição de rigor normativo obteve seu grande marco no ano de 2001, quando Maria da Penha Fernandes ${ }^{1}$ ingressou com denúncia em desfavor do Estado Brasileiro exigindo seriedade nos crimes domésticos (NUCCl, 2015, p.776).

\footnotetext{
${ }^{1}$ [...] Em maio de 1983, dia 29, fui atingida por um projétil de arma de fogo enquanto dormia e que me deixou paraplégica. Após quatro meses hospitalizada retornei para casa, mantida em cárcere privado e quase fui eletrocutada na hora de tomar banho. Depois da descoberta pela Secretaria de Segurança de que o autor do disparo contra a minha pessoa tinha sido o meu próprio marido, por meio de simulação de assalto, e posteriormente por meio de um chuveiro elétrico propositadamente danificado, iniciei minha luta por Justiça, que demorou 19 anos e seis meses para Colloquium Socialis, Presidente Prudente, v. 01, n. Especial 2, Jul/Dez, 2017, p.152-158. DOI: 10.5747/cs.2017.v01.nesp2.s0129
} 
Segundo consta, a autora da demanda ingressou em conjunto com o Centro pela Justiça e pelo Direito Internacional (CEJIL) e o Comitê Latino Americano de Defesa dos Direitos Difusos da Mulher (CLADEM), com denúncia à Comissão Interamericana dos Direitos Humanos da Organização dos Estados Americanos (OEA) (PENHA, 2013, p.05).

A comissão recebedora da peça acusatória teve como uma de suas atribuições, tratar de quebras de acordo internacionais, e no presente caso, condenou o Brasil exigindo simplicidade nos procedimentos processuais penais sem prejudicar os princípios do devido processo legal (BIANCHINI, 2016, p.125).

Certamente a decisão é inquestionável, tendo em vista, que a Constituição Federal de 1988 , atribuiu menção expressa no artigo $5^{\circ}$, inciso I e artigo 226 , $\S 8^{\circ}$ manifestando que o Estado assegurará assistência à família criando mecanismos para coibir violência no âmbito de suas relações.

\section{A INTERPRETAÇÃO DA IGUALDADE MATERIAL DA LEI 11.340 DE 2006}

A Lei 11.340 de 2006 incorporou o tratamento rigoroso em crimes contra a mulher cometido em razão do gênero, restando a doutrina ${ }^{2}$ discutir sobre a constitucionalidade da lei, pois, como é praxe, o artigo 50, inciso I da Constituição Federal expressa a interpretação formal do conceito de igualdade na oportunidade em que diz "homens e mulheres são iguais perante a lei".

Expõem bem a problemática Novelino $(2014$, p.475) no momento em que aduz sobre a singularidade do princípio da igualdade, enaltecendo a carência de proteção material.

Para autores como Nucci (2015, P.780); Bianchini (2016, p.136) e Sarlet (2016, p.583) a constitucionalidade justifica-se no princípio da isonomia e para os casos da minoria é imprescindível a proporcionalidade, pois, tendo em vista o objetivo da lei 11.340/06, que é de dar rigor em casos em que a vítima, detentora da vulnerabilidade, está exposta a agressões físicas e psicológicas, verifica-se que a desigualdade é fundada em dar igualdade em casos desiguais motivadas pela violência de gênero.

Logo, tratar os iguais como iguais e os desiguais como desiguais na medida em que se desigualam encontra-se em consonância na observância da proporcionalidade e igualdade material, restando ao interprete constitucional a relatividade contida no texto normativo. (MORAIS, 2013, p.37).

Explica bem Morais (2013, p.36) e Sarlet (2016, p. 574) na análise constitucional do princípio de igualdade na oportunidade em que apontam a tríplice finalidade limitadora em relação ao legislador, as autoridades públicas e o particular, ou seja, a igualdade perante a lei compreende na proibição de discriminação de qualquer natureza, igualdade na lei e entre a própria lei.

Por tanto, a constitucionalidade já consolidada no ordenamento jurídico brasileiro, justifica-se através da interpretação da igualdade material devido a finalidade de impor tratamento rigoroso em casos em que a violência ocorra por decorrência da violência de gênero, daí a necessidade de aflorarmos a definição da violência de gênero que não se limita apenas a mulher, como veremos adiante.

\section{O CONCEITO DE VIOLÊNCIA DOMÉSTICA}

O conceito de violência doméstica encontra-se no artigo 5o e 7으 da Lei 11.340 de 2006, e apesar da leitura taxativa do preceito primário indicar a existência dos três elementos sendo a

acontecer (faltavam seis meses para o crime prescrever).Ressalte-se que a prisão do meu agressor só aconteceu em outubro de 2002 por conta de pressões internacionais [...] (PENHA, 2013, p.03).

${ }^{2}$ Cunha 2010, p.1165

Colloquium Socialis, Presidente Prudente, v. 01, n. Especial 2, Jul/Dez, 2017, p.152-158. DOI: 10.5747/cs.2017.v01.nesp2.s0129 
prática de qualquer forma de violência em razão do gênero contra a mulher em seu ambiente familiar e doméstico, exige-se do interprete especial atenção no elemento violência de gênero.

Para Nucci $(2015$, p.780) o legislador foi infeliz no conceito de violência de gênero quando diz "é ininteligível para o contexto e totalmente inapropriado", pois, é dificultosa a identificação da motivação do agressor principalmente quando estamos diante da generalidade das diversidades do ambiente familiar.

Isto por que a família brasileira é integrada por variadas religiões, raças, cores, etnias, e gêneros, e sob esse prisma, passou a ser analisado situações em que o gênero feminino não seria a única finalidade da lei, mas sim, todas as pessoas vulneráveis e hipossuficiente por consequência do gênero, ademais, o parágrafo único do artigo 5o da lei em comento já aponta: "As relações pessoais enunciadas neste artigo independem de orientação sexual", como também, o artigo 2음 quando menciona: "independentemente de classe, raça, etnia, orientação sexual".

Apesar da dificuldade interpretativa do texto legal, vários exemplos na doutrina e jurisprudência ${ }^{3}$ evidenciam a diversidade e dificuldade de encontrar a violência de gênero para a imposição da Lei 11.340/2006.

Com o objetivo de apresentar a presença da violência de gênero Nucci (2015, p.780) procura através de exemplos demonstrar a discriminação do gênero feminino na oportunidade em que um roubo praticado por autor desconhecido pela vítima não pode ser tratado da mesma forma como um roubo praticado por uma pessoa que se enquadra no conceito de violência de gênero.

Ocorre que a Lei 11.340/2006, procura agravar crimes em que a vítima esteja em uma posição de vulnerabilidade, logo, essa vulnerabilidade é manifesta no momento em que a vítima não desconfiava que uma pessoa do seu núcleo familiar ou afetivo pudesse cometer um crime em sua própria residência.

Por tanto, conforme presente na doutrina e jurisprudência, verifica-se que a violência de gênero é elemento essencial e discriminador para a imposição do tratamento de rigor imposto pela Lei 11.340 de 2006, tendo em vista o seu conceito ser extraído da vulnerabilidade e hipossuficiência.

Registra-se ainda, que as disposições contidas na Lei 11.340 de 2006 também se aplicam as crianças $^{4}$, aos idosos e nas relações homoafetivas (art. 2ㅇ) ), pois o critério que afasta o tratamento especial consiste na violência de gênero.

3 TJ-MS - Conflito de Jurisdição CJ 16014447020158120000 MS 1601444-70.2015.8.12.0000 (TJ-MS)Data de publicação: 15/03/2016 Ementa: CONFLITO NEGATIVO DE COMPETÊNCIA - VIAS DE FATO PRATICADAS POR FILHO CONTRA GENITORA - CONDUTA CONCRETAMENTE PERMEADA DO PROPÓSITO DE OPRESSÃO AO SEXO FEMININO VIOLÊNCIA DE GÊNERO - INCIDÊNCIA DA LEI N. 11.340/06 - CONFLITO PROCEDENTE. 1. A violência doméstica ou familiar é caracterizada pela ação ou omissão baseada no gênero, circunstância que pressupõe uma relação de superioridade ou objetifcação da mulher pelo homem, em decorrência da discriminação do sexo feminino. $\mathrm{Na}$ hipótese dos autos, de acordo com os elementos informativos colhidos na fase investigatória, o agressor, após uma discussão, empurrou a vítima, sua genitora, fazendo com que a mesma caísse no chão. Desse modo, verificando-se em tese - a ocorrência de contravenção de vias de fato contra mulher praticada em decorrência de sua vulnerabilidade e no âmbito de relação íntima de afeto, tem-se como presentes os requisitos caracterizadores da violência de gênero, atraindo, pois, a competência de uma das Varas de Violência Doméstica ou Familiar contra a Mulher da Comarca de Campo Grande. 2. Conflito julgado procedente para declarar a competência do Juízo da 2a Vara de Violência Doméstica ou Familiar Contra a Mulher de Campo Grande. COM O PARECER

${ }^{4}$ HABEAS CORPUS. IMPETRAÇAO COMO SUCEDÂNEO DE RECURSO. IMPROPRIEDADE DA VIA ELEITA. AGRESSAO DE PAI CONTRA DUAS FILHAS ADOLESCENTES. COMPETÊNCIA. LEI MARIA DA PENHA. APLICABILIDADE. AUSÊNCIA DE ILEGALIDADE PATENTE. NAO CONHECIMENTO. STJ - 31.05.2013. 2. Agressão praticada pelo pai contra duas filhas (adolescentes), sob o teto da família, atrai a incidência do art. 5o da Lei Maria da Penha, não havendo, por conseguinte, ilegalidade na decisão impugnada.

Colloquium Socialis, Presidente Prudente, v. 01, n. Especial 2, Jul/Dez, 2017, p.152-158. DOI: 10.5747/cs.2017.v01.nesp2.s0129 
Quando abordado sobre a incidência da lei em relação aos transexuais Cunha e Pinto (2010, p.1180), aduz que a lei foi inovadora devido a realidade das convicções de nosso país, restando o amparo normativo do artigo 5o, inciso II, abranger o critério de gênero e o vínculo de afinidade, afastando as limitações imposta pelo critério físico.

Por sua vez, Biachini (2016, p.59), posicionou-se favoravelmente, fundamentando que na ocorrência de relações de pessoas transexuais ${ }^{5}$, e havendo os três passos para a configuração do conceito legal: violência doméstica, questão de gênero, o amparo especial é medida que se impõem.

Logo, se verifica que é indiferente o conhecimento de que a vítima seja mulher ou homem, basta que a violência seja baseada no gênero, conforme vimos nas jurisprudências de pessoas transexuais e o pai que agredi as suas filhas, concluindo assim, que gênero e sexo biológico não se confundem, ou seja, não é por ser do sexo feminino, significa que o gênero é suscetível de fragilidade em comparação ao homem, já havendo jurisprudência da aplicação da Lei 11.340/2006, em que o homem é a vítima e a mulher a agressora ou em casos de relação homoafetiva entre duas mulheres.

Sendo o crime precedido de violência de gênero, resta identificar no fato as demais características existentes no artigo 50 inciso I,II e III da Lei 11.340 de 2006.

Para Nucci $(2015$, p.781), Bichini $(2016$, p.36) e Cunha e Pinto $(2010$, p.1175) trata-se de ambiente doméstico o local em que a vítima tem ânimo de domicilio, ou seja, o local em que a vítima descansa e confia em expor suas intimidades sem que terceiros interfiram em seu ambiente, ou seja, sem qualquer receio, quanto ao âmbito familiar, corresponde a subjetividade encontrada nos vínculos de parentesco, afinidade e afetividade.

A importância da compreensão do âmbito da unidade doméstica e familiar tem o seu valor justamente em casos em que a vítima e o agressor nunca coabitaram juntos, porém devido ao laço íntimo de afeto incide as imposições da Lei 11.340/06 como no caso de namorado, parentes próximos como tios e irmão e empregada doméstica.

Logo, ausente a coabitação e presente o laço intimo entre autor e vítima verifica-se que não afasta a lei especial ${ }^{6}$, assim como, ausente o laço íntimo e presente a coabitação também se aplica as imposições especiais.

\section{CONCLUSÃO}

A Lei 11.340 de 2006 abarcou em seu texto normativo tratamento diferenciado em crimes cometidos no ambiente doméstico e familiar contra a mulher mediante precedente discriminação de gênero.

Entretanto, para elucidar o assunto vimos a evolução histórica do princípio da igualdade nas constituições federais antecedentes através do debate de igualdade formal e material, bem como, as motivações para a incorporação da Lei 11.340 de 2006 no ordenamento jurídico brasileiro apresentado a história de Maria da Penha Fernandes e a sua luta pelos direitos humanos das mulheres.

\footnotetext{
${ }^{5}$ TJ-SP - MS: 20973616120158260000 SP 2097361-61.2015.8.26.0000, Relator: Ely Amioka, Data de Julgamento: 08/10/2015, 9ạ Câmara de Direito Criminal, Data de Publicação: 16/10/2015.

6 TJ-RS - Conflito de Jurisdição CJ 70063545578 RS (TJ-RS) Data de publicação: 09/07/2015 Ementa: CONFLITO NEGATIVO DE COMPETÊNCIA. VIOLÊNCIA DOMÉSTICA. AMEAÇAS E AGRESSÕES PERPETRADAS POR IRMÃO CONTRA IRMÃ. Ausência de coabitação que não inviabiliza a incidência da Lei 11.340/06. Indícios concretos de vulnerabilidade da ofendida. CONFLITO JULGADO PROCEDENTE. (Conflito de Jurisdição № 70063545578, Terceira Câmara Criminal, Tribunal de Justiça do RS, Relator: Sérgio Miguel Achutti Blattes, Julgado em 16/04/2015).

Colloquium Socialis, Presidente Prudente, v. 01, n. Especial 2, Jul/Dez, 2017, p.152-158. DOI: 10.5747/cs.2017.v01.nesp2.s0129
} 
Logo, passamos a analisar o conceito de violência do gênero contido no artigo 5ㅇ e 7으 da Lei 11.340/06, e através do conhecimento doutrinário e exemplos da jurisprudência verificamos que para que um determinado caso seja tratado com a rigorosidade da lei, exige-se a necessidade de encontrar a violência de gênero, ambiente doméstico ou familiar vinculados por um laço de intimidade.

Sendo assim, o resultado do presente estudo se justifica na constitucionalidade da lei através da igualdade material que diante do conhecimento apresentado restou sanado a compatibilidade e a necessidade de tratar crimes de violência doméstica desigualmente a casos comuns devido a presença da violência de gênero.

\section{REFERÊNCIAS}

BIANCHINI, A. Lei Maria da penha: lei n. 11.340/2006: Aspectos assistenciais, protetivos e criminais da violência de gênero, 3. ed. São Paulo: Saraiva, 2016.

CUNHA, R: PINTO, R. Legislação criminal especial, 2. ed. São Paulo: Revista dos tribunais, 2010.

JESUS, D. Violência contra a mulher: Aspectos criminais da lei n.11.340/2006, 2. ed. São Paulo: Saraiva, 2015.

MORAIS, A. Curso de direito constitucional, 29. ed. São Paulo: Atlas, 2013.

NUCCl, G. Leis penais e processuais penais comentadas, 9. ed. Rio de Janeiro: Forense, 2015.

SARLET, I: MARINONI, L: MITIDIERO, D. Curso de direito constitucional, 5. ed. São Paulo: Saraiva, 2016.

BRASIL.SuperiorTribunaldeJustiça.HABEASCORPUS2010/0125851-1 HABEAS CORPUS. IMPETRAÇÃO COMO SUCEDÂNEO DE RECURSO. IMPROPRIEDADE DA VIA ELEITA. AGRESSÃO DE PAI

CONTRA

DUASFILHASADOLESCENTES.SEXTATURMA,Relatora:MariaTherezadeAssimMoura.31.05.2013.Disp onívelem:http://www.sti.jus.br/sCON/jurisprudencia/doc.jsp?livre=Agressao+de+pai+contra+filha $\& b=A C O R \& p=$ true $\& l=10 \& i=3$. Acesso em: 20 jun. 2017.

BRASIL. Tribunal de Justiça do Estado do Mato Grosso do Sul. 2o vara de violência doméstica ou familiar contra mulher da comarca de Campo Grande, Conflito de Jurisdição CJ 16014447020158120000 MS 1601444-70.2015.8.12.0000 CONFLITO NEGATIVO DE COMPETÊNCIA -VIAS DE FATO PRATICADAS POR FILHO CONTRA GENITORA Relator: Des. Francisco Gerardo de Sousa, 3a Câmara Criminal de Campo Grande. 15 de março de 2016. Disponível em: https://tj-ms.jusbrasil.com.br/jurisprudencia/322111307/conflito-de-jurisdicao-cj16014447020158120000-ms-1601444-7020158120000. Acesso em 01 mai. 2017.

BRASIL. Tribunal de Justiça do Estado do Rio Grande do Sul. CJ 70063545578 RS. CONFLITO NEGATIVO DE COMPETÊNCIA. VIOLÊNCIA DOMÉSTICA. AMEAÇAS E AGRESSÕES PERPETRADAS POR IRMÃO CONTRA IRMÃ. Terceira câmara criminal. Publicado no dia 09.07.2015. Relator: Sérgio MiguelAchuttiBlattes.Disponívelem:https://tjrs.jusbrasil.com.br/jurisprudencia/206874930/conflit o-de-jurisdicao-cj-70063545578-rs. Acesso em: 09. jul. 2017. 
BRASIL. Tribunal de Justiça do Estado de São Paulo. Mandado de Segurança no 209736161.2015.8.26.0000, da Comarca de São Paulo Impetrante: Gabriela da Silva Pinto Nome social Jean Carlos da Silva Pinto nome civil. Impetrado MM. Juiz do juizado da violência doméstica e familiar contra a mulher. Acórdão TJSP (08/10/2015) - mandado de segurança - indeferimento de medidas protetivas - impetrante socialmente do sexo feminino - violência de gênero - segurança concedida. 08.10.2015. 9ạ Câmara de Direito Criminal Relator Ely Amioka. Disponível em: http://www.compromissoeatitude.org.br/acordao-tjsp-08102015 mandado-de-segurancaindeferimento-de-medidas-protetivasimpetrantesocialmente-do-sexo-feminino-violencia-degenero-seguranca-concedida/. Acesso em: 08 jun. 2017. 